\title{
DEBATENDO O PONTO DE VISTA PRÁTICO-POIÉTICO DE CRISÓSTOMO
}

\section{LEONARDO JORGE DA HORA PEREIRA ${ }^{1}$ E JOSÉ CRISÓSTOMO DE SOUZA}

\begin{abstract}
RESUMO: O debate começa pelo questionamento, por Leonardo Pereira, do possível caráter abstrato, demasiado geral, da noção, central à posição prático-poiética de Crisóstomo de Souza, da ação humana como poiésis e de nosso envolvimento básico com o mundo como um emaranhamento sensível prático criativo, de cujo caráter poderia resultar um déficit explicativo e também normativo. E se desenvolve no questionamento da atribuição àquela ação de um caráter de produção de artefatos, e também da atribuição de um alegado caráter artefatual à própria realidade humana, que então não poderia ser propriamente apreendida como estrutura ou sistema, condicionamento e circunstância. Que assim tampouco poderia ser criticada - no marco do que parece ser um viés idealista romântico - por suas eventuais deformações nesse nível, em termos p. ex. de alienação, ocultação etc. Nesse quadro, a técnica tampouco seria suficientemente criticada por sua eventual dependência de uma nociva metafísica objetivista ou por sua determinação pelas imposições da ordem capitalista. Para Crisóstomo, que oferece em traços rápidos uma interpretação diferente para cada um desses casos, tais desafios resultam mais bem explicados na consideração do conjunto de seus textos mais recentes sobre seu ponto de vista prático. Que, admite Leonardo, poderia ter interesse como uma bem-vinda ruptura com posições tanto positivistas como linguocêntricas. $\mathrm{Ou}$, em vez disso, ainda poderia permanecer presa a reducionismos próprios a outro paradigma produtivo, o de Marx. Mas, para Crisóstomo, suas noções de poiésis e intencionalidade sensível na verdade enriquecem uma noção mais material, efetiva, normativa, de autonomia humana, como suporte para uma noção transformativa mais promissora, crítica e inovadora, de democracia e de cidadania materiais, para além daqueles três paradigmas.
\end{abstract}

PALAVRAS-CHAVE: ponto de vista prático-poiético; potencial explicativo e normativo; variedades de atividade humana; realidade como artefato e objetivação; autonomia material como critério normativo.

ABSTRACT: The debate starts with Leonardo Pereira"s questioning the possibly abstract and too general character of Crisóstomo de Souza's notion of human action as basically poiesis, central to his poietic-pragmatic philosophical position, as well as his notion of our relations with the world as a poietic-pragmatic entanglement, which would them be marked by a deficit of both normative and of explicative powers. Then it further develops by challenging the attribution to human action of a constant character of production of artifacts, as well as by the

\footnotetext{
${ }^{1}$ Professor de filosofia da Universidade Federal da Bahia (UFBA). Pesquisador associado do Laboratorio Sophiapol da Universidade de Paris-Nanterre. Doutor em filosofia pela Université Paris Nanterre. E-mail: leonardo.jorge@ufba.br.

${ }^{2}$ Professor titular de Filosofia da Universidade Federal da Bahia (UFBA). Coordenador do Grupo de Pesquisa Poética Pragmática e membro do Centro de Estudos Dewey e Pragmatismo. Doutor em filosofia pela Universidade Estadual de Campinas (UNICAMP). E-mail: josecrisostomodesouza@gmail.com.
} 
attribution of an artefactual character to human reality itself, that then couldn't be apprehended and criticized as structure and system, within what seems to be romantic idealistic paradigm, in terms of alienation, hypostatization etc. Likewise, technology doesn't appear to be critically dealt with in Crisóstomo's position, in its possible association with bad objectivistic metaphysics or in its implications with impositions of the capitalist system. For Crisóstomo, who offers in rapid traits a different answer for each one of these challenges, they are better explained in a set of his recent works taken as a whole. Which at the same time, Leonardo admits, may well provide a worthy overcoming for both dogmatic, positivistic empiricism, and for linguocentric, idealistic philosophical positions. Or, instead, still fall into reductionisms that plague the Marxian version of productive Materialism. According to Crisóstomo, the suggested elements of poiesis and sensible intentionality of his paradigm do enrich his point of view with a more material, effective, normatively rich notion of autonomy, critically and innovatively apt to support a transformative and more promising notion of material democracy and citizenship.

KEYWORDS: practical poietic point of view; explicative and normative potential; varieties of human activity; reality as artifact and objectification; autonomy as normative criterion.

1-LEONARDO: De um modo geral, para problematizar o elemento central de seu ponto de vista filosófico, eu questionaria o caráter talvez demasiado geral e abstrato de sua concepção de atividade humana e de nossa relação com o mundo, em suma, do que você chama de holismo prático-material. Acredito que daí decorre boa parte das dúvidas ou dificuldades que enxergo em sua proposta.

CRISÓSTOMO: Se esse é o ponto central, certamente irá sendo mais esclarecido ao longo da sucessão das respostas a suas outras perguntas. Mas, desde já, não me parece incomum que na articulação de um ponto de vista filosófico prevaleça uma afirmação básica central muito geral (como a de que somos essencialmente vontade de potência ou espontaneidade, ou de que tudo é linguagem ou tudo é intuição sensível) e que isso represente um esforço aceitável, produtivo, de simplificação, particularmente quando escapa a pretensões metafísicas e monopolistas. No meu caso, junto com a insistência numa caracterização da atividade humana como poiésis, também minha escolha e reiteração de expressões como ponto de vista e paradigma para a compreensão que proponho, assume um caráter contingente, não exclusivista. E creio que o mesmo pode valer para o eventual interesse heurístico da minha ideia de relação homem-mundo como centralmente um emaranhamento prático, sensível, poiético, social com ele, não distante de noções de conhecimento como em primeiro lugar know how, e ação como "lidar com" (do pragmatismo), ou do papel particularmente relevante da atividade produtiva (para mim, entretanto, bem diferente de Marx). Uma ideia de ação humana, e das práticas em que se articula, para mim bem menos abstrata do que, p. ex., a noção empirista da experiência 
e do nosso correspondente contato com o mundo (passivo, intuicionista sensível, atomista, representacionista), ou a de que, ao contrário, tudo é linguagem, de que apenas pela linguagem se dá nossa relação básica de desvelamento com o mundo. Noções que, entretanto, nem por isso vejo como desprovidas de interesse nem de alguma verdade. Sou hegeliano, você sabe.

2 - LEONARDO: Você caracteriza a ação humana como pervasivamente poiésis. Mas, para não citar Weber, Durkheim e outros clássicos (ou contemporâneos) da sociologia, em uma filósofa como Arendt (ou mesmo em Habermas) encontramos uma compreensão mais diversificada da ação humana, há espaço para práxis como distinta de poiesis etc.

CRISÓSTOMO: Para mim a ideia de pervasividade (qualidade, aliás, bastante indeterminada) de um certo aspecto, aquele poiético, na ação humana, não exclui uma diferenciação de tipos de ação - acho que até a pressupõe. Absolutamente não exclui a discussão de uma classificação por tipos, ou várias classificações, sempre provisórias, contingentes e nada monopolistas, porque históricas. Estou do lado de Arendt enquanto acho essa uma tarefa filosófica relevante, das tantas que eu gostaria que meu trabalho pudesse fomentar entre nós filósofos no Brasil. Mas não acho que nada disso exclua que se reconheça, em todos ou muitos daqueles eventuais tipos de ação, um aspecto poiético, de, como digo, "introdução no mundo, pela ação humana, de algo que lá não estava" - ou seja, de criação. Quando menos por contraponto à - quiçá até aristocrática, classista, grega - visão da práxis como verdadeira atividade exemplarmente humana, livre, universal, superior, visão à qual poucos fazem reparos, mesmo quando ela vem caracterizar, sozinha, positivamente, um grupo inteiro de correntes filosóficas, como filosofias da práxis. Aliás, não só uma rica distinção e classificação de tipos de ação humana sobremodo nos interessa, mas igualmente uma - tão rica quanto - dos tipos de objetos e objetivações resultantes dela ou envolvidas nela (isso, sim, frequentemente descuidado na filosofia), que, nesse envolvimento usuário, se diferenciam. Isso para além do proposto por Marx no nível econômico, que praticamente não vai além de dois tipos bem distintos de objetos, por seus usos, bens de produção, que engendram relações sociais relevantes, e bens de consumo, que não o fariam.

3 - LEONARDO: Quanto à atividade, em Arendt temos uma riqueza muito maior; encontramos as lógicas da reprodução (trabalho/labor), da produção (obra/fabricação), da ação (agonismo, diálogo, imprevisibilidade, promessa, perdão) e do pensamento e juízo (consigo próprios). No final das contas, por mais que você critique Marx, essa concepção de um novo 
paradigma da produção, da poiésis, não é ainda por demais marxista? Por que reduzir tudo a um paradigma específico de ação? Isso não diminui o potencial heurístico e explicativo desse seu paradigma?

CRISÓSTOMO: Não vejo problema em acolher e testar sugestões como as de Arendt nesse terreno, aliás, ela, um admirável tipo de filósofa ensaística, jornalista, produtiva, não obstante seu classicismo idealista. Que tal perguntar-se p. ex. por um possível elemento poiético-produtivo, eventualmente criador, além de defensavelmente sensível, nos diversos tipos de ação - quiçá mesmo no diálogo e no perdão - da classificação de Arendt? Afinal estou propondo, junto com uma chave para eventual assimilação crítica, reconstrutiva, de muito do que dizem outros filósofos, apenas um esboço de núcleo conceitual, em apenas um par de páginas, que você tão produtivamente comenta, em que entretanto muita coisa necessariamente ainda fica por se desenvolver ou mesmo simplesmente registrar. Pois trata-se de um ponto de vista que quer ter, entre outros, o caráter de um work in progress, de uma pauta de pesquisa, oxalá mobilizadora, crítica, um work in progress cujo desenvolvimento você agora com seus questionamentos valorosamente promove.

Quanto à sua dúvida sobre se meu ponto de vista, pretendendo-se crítico de Marx, não seria ainda, sobre a ação, por demais marxista, entendo antes o contrário. Com efeito, como aponto em outro texto meu, o aparentemente poiético-produtivo Marx distingue dois tipos de prática/ação, essencialmente opostos. 1) A que parece ser mais propriamente produtiva, do comum dos homens, com que mais simpatizo, ele a toma e condena como "judaica" e "suja" i.e. particular, egoísta, não universal. 2) A ação superior para ele é justamente a outra, a famosa e digna de uma denominação grego-clássica - práxis: a prática crítico-revolucionária, que em Marx podemos entender como teórica, filosófica, universal - e, finalmente, essa sim, para ele, verdadeiramente humana. Meu ponto de vista, ao contrário, trata de aproximar as duas, como atividades fazedoras, a primeira talvez até mais geral e formadora, além de, para mim, dimensão inevitável também para a outra.

4 -- LEONARDO: Você diz que todas as nossas ações resultam em última análise em artefatos e objetivações nossas, produzindo-nos a nós próprios e ao mundo como artefatos. Toda lógica e ação social pode-se resumir a isso? a produção de artefatos?

CRISÓSTOMO: Tanto no meu texto como mesmo na sua pergunta aquela lógica inclui também pelo menos a "produção" dos homens por uma dada objetividade social, por dadas condições sociais. Mas o fato de tal objetividade, também objetivação, ter um caráter prático- 
ativo-subjetivo, até para o determinista e às vezes materialista cartesiano Marx (que vai denunciar sua absoluta fixação, no Capitalismo, a ser superada apenas no/pelo Comunismo), sugere que ela pode ainda ser de algum modo concebida e tomada como plástica, transformável - mesmo se de modo "condicionado" por ela mesma, mas, pace Marx, não simplesmente prescrito por ela. De toda maneira, é bom não esquecer que me refiro também a objetivações, junto com artefatos, para as quais podemos razoavelmente admitir uma marca de artefatualidade, além de, vice-versa, para a artefatualidade um caráter de objetivação. Do mesmo modo, vale ter em conta que o que faço aqui é também um contraponto ao desinteresse da filosofia política e mesmo social, nos nossos dias, pela dimensão poiética e material, objetual, das diversas práticas humanas ou de boa parte delas. Essa sim uma lamentável abstração monopolista que hoje em dia se desdobra na redução de contexto à intersubjetividade desencarnada (linguagem), de um lado, e à substância (sem sujeito), de outro. O que para mim resulta na fixação de boa parte da filosofia contemporânea num desmaterializado, descorporeizado e reducionista paradigma linguocêntrico, intelectualista, tanto a respeito de contexto como de nossa ação relevante e nosso envolvimento com o mundo.

5 - LEONARDO: Uma outra consequência do que me parece ser essa sua concepção monista da atividade/ação humana é que não vemos nela nenhum critério de distinção entre épocas históricas, tudo resulta muito homogeneizado...

CRISÓSTOMO. Bem, a essa altura eu esperaria que você já não visse minha concepção de ação humana como tão abstrata, monista, reducionista, homogeneísta ou coisa parecida. Mas em vez disso uma concepção de realidade humana como material-espiritual, prática, não dualista, pluralista, constituída por uma exuberância "leibniziana" de distintos tipos de objetos, práticas e pontos de vista, em sua diversidade, multiplicidade, mutabilidade, contextualidade. Quanto a épocas, seja dito que o que procuro pintar é em primeiro lugar um quadro modernista da Modernidade e de suas exuberantes possibilidades produtivas-criativasautonomistas. Mesmo assim, me parece que a criação de novos artefatos (materiais-espirituais) é o que mais dá conta de nossa própria e geral, contínua, historicidade, é a razão por que temos história, uma história aberta que é permanente variação, mudança, inovação. Imagino, porém, que não só os objetos como seu papel e suas relações com práticas, e essas mesmas práticas, necessariamente variam muito no tempo e no espaço, no modo de se diferenciarem e articularem entre si (sistema, contexto material). Como sugere uma variedade de denominações epocais-objetuais, como paleolítico, neolítico, revolução agrícola, revolução industrial, idades 
de ferro, bronze etc. - com suas claras associações de desenvolvimentos e épocas históricos inteiras a nossas realizações poiético-objetuais, como o fogo, a roda, a caravela, a pólvora, a imprensa, o automóvel, o computador, o celular, mas também “espirituais”, para mim, cooperativamente, inseparáveis das primeiras, como a reforma protestante, a revolução francesa, a mídia, a cidade etc. Não sei se você com sua pergunta está-se referindo a diferentes etapas ou estágios histórico-dialéticos à la Marx, objetualmente determinados, que entretanto, mesmo ele, define-as todas como modos de produção de artefatos por recurso a artefatos, mas, ainda assim, e por isso mesmo, como diferentes estágios históricos e modos de vida. Quanto a isso não tenho nada a oferecer, uma concepção qualquer abrangente de História como coisa unitária, dividida em uma sequência de estágios necessários. De sorte que, nesse terreno, mais me interessaria, em vez disso, como filósofo, inteirar-me do que têm desenvolvido nessa área historiadores e antropólogos mais empíricos, da técnica, da cultura, da sociedade etc. Sou um neo-hegeliano conciliado com exigências empiristas, nominalistas, experimentalistas, para conhecimento e compreensão das coisas.

6 - LEONARDO: Se a sociedade é artefato, como ficam para você as estruturas condicionantes? como fica o sistema? Considerar a sociedade como simplesmente produto da ação humana, como um artefato, não é muito romântico? Não haveria então espaço para a contingência, para efeitos não pretendidos da ação? E para um diagnóstico de eventuais estruturas alienadas (não no sentido essencialista, mas no de escaparem de nossa intencionalidade, de nosso controle consciente)?

CRISÓSTOMO: Sim, já me referi acima a uma objetividade social, mesmo enquanto envolvendo uma dimensão artefactual, mas podendo junto com isso ser entendida como condicionante de nossas ações, isto é, como sistema ou estrutura. Sistema ou estrutura que eu, pelo meu ponto de vista, absolutamente não imagino possa ser mudado à vontade, ou de modo total, num momento dado, por um Macro-Sujeito também total, e trazida para seu Controle Consciente. Muito menos que isso ocorra lógico-dialeticamente, por Inversão de Inversão, Negação de Negação, ou qualquer outra representação especulativa, teológica, de Revolução. $\mathrm{Na}$ sua pergunta, você parece reclamar por estrutura, talvez mesmo por macrocondicionamentos apropriáveis por uma Grã-Teoria Crítica e uma Mega-Prática correspondente, logo por algo como Controle Consciente de uma Totalidade finalmente assim desalienada. Enquanto ao mesmo tempo reclama pelo reconhecimento de contingências, efeitos inevitavelmente imprevisíveis, parcialidades, criação. Quanto a mim, não entendo objetividade 
social, condições e condicionamentos da realidade como operando nada daquele primeiro tipo; tendo mais, francamente, para sua outra alternativa. Então, você tem razão, pode-se ver no meu ponto de vista filosófico uma pitada de indeterminismo, liberdade, romantismo, de ênfase nas noções de imaginação, de criação, contingência, particularidade, indeterminação em última instância (contra Marx) etc. Entretanto, na verdade, sem nada a ver com românticas e onipotentes infinitudes subjetivas, de gênios e heróis, de super-vanguardas dirigentes da História, nem outros delírios grandiloquentes, voluntaristas e anarquistas, às vezes apocalípticos, em geral alemães, no fim, na prática, francamente elitizantes e antidemocráticos.

7 - LEONARDO: Não vejo espaço na sua proposta para nenhum critério normativo para crítica de formas de vida, de práticas sociais, como vejo em Rahel Jaeggi, a quem você menciona como próxima, em alguns aspectos, de sua posição. Parece que, no seu paradigma, todos os tipos de prática normativamente se equivalem, que, assim, "todos os gatos são pardos", que tudo vale a mesma coisa.

CRISÓSTOMO: Certamente há critérios normativos, todos os seres humanos nãofilósofos também os têm, ninguém passa sem eles, para tudo quanto é prática. A questão é conceber de onde os tiramos e como filtrá-los, torná-los efetivos, realizá-los. Quanto a isso, você sabe, não sou um fundacionista forte, transcendental, anti-pluralista, não-experimentalista. O que entretanto não tem absolutamente nada a ver com ser anômico, relativista ou gatopardo, embora envolva ser pluralista, destrancendentalizado e historicista. Portanto eu os tiro, aos critérios normativos, de onde todos os tiram: prudencialmente, da experiência, do nosso tempo e do nosso contexto - e voltados para eles. Da experiência, própria e acumulada, prudencialmente avaliada, de pertencimento a uma forma de vida compartilhada, a determinada conjuntura, diante de determinado problema. Apenas, como filósofo, tenho mais tempo para me ocupar em examinar e articular conceitualmente sugestões normativas, buscar justificar e testar mais amplamente algumas, em discussões, e por uma reflexão mais exigente sobre mais experiências e mais noções, e uma variedade de ideias e opções que temos sobre essas coisas todas. Rahel Jäggi, me parece, toma como critério para a avaliação de práticas os propósitos que nós definimos para elas, como elas os realizam, satisfatoriamente ou não, se para isso têm capacidade de se renovar, uma avaliação de seu sucesso em termos de solução de problemas sentidos e caracterizáveis pelos concernidos, em processos políticos, sociais e culturais.

Ligado a isso, tomo as sensibilidades da cultura moderna a respeito, envolvendo parâmetros como igualdade, autonomia, iniciativa, justificação, reconhecimento, inclusão, 
diversidade, distribuição, produtividade, criação, liberdade etc. Sugestões acumuladas numa rica, longa e particular experiência histórica, ocidental, hoje habitando a cultura que nos cerca e que em parte globalmente se generaliza. Mas também tendo em conta, de modo aberto, nossas vontades e expectativas de invenção e sonho para adiante - digamos, nosso futurismo. Ou seja, pelo que eventualmente um uso não despótico, não violento, da imaginação possa oferecer como vislumbre de possibilidades de algo melhor, frequentemente empurradas ou abertas por desenvolvimentos objetivos. Para mim, algo assim está bom. Entretanto, acho que Rahel, além de outros déficits, que têm a ver com sua filiação a uma questionável tradição teórica particular, a Teoria Crítica, e com seu pertencimento a um contexto econômico e tecnicamente muito particular, do super-desenvolvido, norte-atlântico, do qual olha o mundo, perde em não considerar nisso tudo uma participação dos objetos e de sua produção, bem como, para mim, perde também por "ascetismo nórdico" (em comparação com nossa brasileira inclinação sinnliche, feuerbachiana, sensível, para as coisas), mas disso não falaremos agora. Se ela me ouvir, vai tornar mais materialista (como ela gostaria), hegeliano em sentido mais promissor (o que ela também gostaria), mais efetivo, seu modo de pensar sobre formas de vida, suas crises e superações - e sua crítica e transformação.

8 - LEONARDO: Uma outra possível consequência mais ampla de seu holismo materialista seria que, se ele tem um papel importante de crítica e ruptura com Marx, e também, de outro lado, ruptura com os idealistas, e ainda com os representacionistas e com os linguocêntricos, podemos ainda assim nos questionar acerca de seu real potencial explicativo. Como disse nosso colega Waldomiro José da Silva Junior, na sessão de discussão de seu texto em sua versão mais condensada, se tudo é prático-poiético, nada é prático-poiético, o potencial explicativo se esvai. Mais uma vez, onde ficariam as distinções analíticas e históricas?

CRISÓSTOMO: De um lado, não num texto de duas páginas, mas, me permita listar, numas trinta, em "O Mundo Bem Nosso" (Cognitio, v.16, n.2, 2015), trato de mostrar mais expressamente, embora ainda resumidamente, como, mais produtivamente, articular-se-iam conhecimento, realidade, fundação, normatividade, atividade etc. no novo paradigma, em oposição, como você registra, ao empirismo dogmático, positivista, e à filosofia hermenêutica mais linguocêntrica. Em outro tanto de páginas, no meu "Teses ad Marx" (Cognitio, PUC-SP, v.13, n.1, 2012), trato de mostrar melhor como meu ponto de vista se distingue do materialismo de Marx, com seu hipertrofiado poder explicativo, normativo, transformador e alegadamente emancipatório, cujas complicadas consequências históricas entretanto conhecemos. Por fim, no 
meu "Sobre o que Pode ou Não Pode um Ponto de Vista Prático em Filosofia" (Cognitio, v.18, n.2, 2017), nas trinta páginas de troca de ideias com o Prof. Waldomiro, sobre seus questionamentos cético-analíticos à minha proposta, discuto mais seu enquadramento metafilosófico - para mim pluralista, prático, antidogmático, falibilista, experimentalista etc. Tudo isso junto (mas particularmente "O Mundo Bem Nosso"), mesmo compreendendo uma exposição ainda tosca, resumida e embrionária, seria impossível repetir aqui, em poucas linhas, como exibição do "potencial explicativo" que o paradigma poiético-pragmático possa ter.

De outro lado, para dar um reconhecimento particular àquele ponto do Prof. Waldomiro evocado por você, creio que caiba entendê-lo, de novo, como uma cobrança por normatividade. Como dizendo que, "se todo agir humano, nas condições atuais, sociais, econômicas etc. já é poiético-criativo, e todos os homens já são em suas atividades criadores poiéticos, o que seu ponto de vista traz por acréscimo, de crítico e transformativo?" - e me agrada muito dizer algo sobre isso porque tenho particular estima por cobranças do tipo "para que serve?", "em que ajuda?". O que posso dizer aqui é que me parece uma estratégia normativa razoável para filósofos não-platônicos, não-fundacionistas, pós-metafísicos, não transcendentalistas, mais efetivamente democráticos, não dissociar inteiramente descrição de prescrição, fato de valor, o que se deve fazer do que já em algum nível ou de algum modo se faz. E isso por um olho dirigido a problemas reais e sentidos, crises e mudanças na própria realidade, tanto quando possibilidades e potencialidades suas, emergentes. Trata-se assim de ver o que deve ser como em alguma medida disposto pelos próprios desenvolvimentos (objetivos-subjetivos) da/na realidade e do tempo. No caso, para mim, a Modernidade, sua variante periférica (Brasil), suas aspirações generalizadas. Isso para sermos nós também, em nossas concepções, históricos, transformativos e efetivos, criativos, produtivos e modernistas - junto com democráticos e experimentais. Há hoje interessantes sugestões para entender o idealismo alemão e o hegelianismo, com mais razão ainda o idealismo francês, do qual ninguém se lembra, como modernismo, e, eu acrescentaria para o nosso caso, desenvolvimentismo (poiético). Também o pragmatismo como modernismo, e o próprio ensaísmo historicista interpretativo brasileiro como discursos da modernidade e também modernismo. Além do próprio Marx, como na recriadora releitura de Marshall Berman (Tudo que é Sólido Desmancha no Ar), a quem propus pessoalmente algumas correções. É na esteira desses desenvolvimentos, de modo bem diverso de boa parte da filosofia contemporânea, que me coloco poético-praticamente. 
9 - LEONARDO: Outro aspecto importante de seu ponto de vista material produtivo, artefactual, é sua concepção de técnica. Ao mencionar Heidegger em relação à usualidade/manualidade, mas também em todo texto, você parece adotar uma concepção um tanto neutra, apenas instrumental, da técnica e dos aparatos técnicos. Entretanto, no próprio Heidegger tardio (o da Ge-stell) e em outros autores, vemos uma concepção da técnica como algo pautado em certas formas fundamentais de relacionamento com o mundo, formas de préconceber o mundo e nós mesmos. Vemos a técnica como invadida e condicionada por metafisicas etc., o que introduz uma distinção até epocal entre técnicas distintas. No Capital, vemos Marx analisar o modo como os meios de produção são moldados pela lógica capitalista de exploração de mais-valia relativa, na nossa época.

CRISÓSTOMO: Acho as noções de mais-valia, fetichismo e alienação, favoritas da chamada teoria crítica, nada mais do que metáforas interessantes, não conceitos, ligadas a diagnósticos falsos cheios de pressupostos dogmáticos pseudo-humanistas, totalmente ingênuos com relação à natureza das opções de "solução" que cobrariam - mas não dá pra discutir isso aqui agora. Não me vejo tampouco participando dos enquadramentos especulativos de Heidegger, de seus pressupostos metafísicos e grão-transcendentais. Mesmo assim, por meu ponto de vista prático-poiético, me vejo algo próximo do momento pragmático de Heidegger, a precedência que ele atribui à Zuhandenheit, usualidade, em relação à Vorhandenheit. Esta implicando certo tipo de objetivismo, representacionismo, cartesianos, também para mim vinculados a uma forma de conhecimento e prática, a da ciência moderna, que pode ter a ver com formas mais gerais de nos relacionarmos com o mundo, no caso da ciência uma forma muito virtuosa e produtiva para certos usos, porém, de outro lado, relativizável e criticável na sua estreiteza e no seu imperialismo. Mas não posso dizer que vou além desse ponto heideggeriano, não obstante certa convergência do poiético-pragmático, corpóreo, humano e historicista, com a hermenêutica e a fenomenologia. Entendo meu ponto de vista e o dele como marcados por particulares contingências de contexto, justificadamente mobilizadoras, bem diversas, que vão em direções bem distintas. Ainda que - como reconheceu nosso arguto colega, nietzschiano e mais, o filósofo André Itaparica - não seria difícil epocalizar mais a minha proposta, como uma grande virada num longo percurso de metafísica racionalistaintelectualista, em oposição a esta, agora como milenar desconhecimento de nosso ser corpóreo, relacional, intramundano, que implica numa outra forma de revelação do mundo.

Entretanto, não obstante minhas inclinações narrativas e historicistas, prefiro encarar o ponto de vista poiético-prático como em primeiro lugar deflacionado e deflacionista, não tendo 
muito a oferecer à altura de um ponto de vista de Deus - ou do Ser. Nesse campo, digamos, romântico, tenho preferido, cosmopolita e ecumenicamente, olhar mais, embora sempre criticamente, para o desprezado idealismo francês, modernista, com suas filosofias mais leves e modestas, da ação e da criação. Olhar também a obra do nosso Álvaro Vieira Pinto, que essa então quase ninguém sequer mesmo admitiria ler. Quanto a Marx e seus epocalíssimos (e apocalípticos) diagnósticos especulativos, de alienação e correlatos, que vão muito além de seu sensato materialismo prático, preferiria não me estender no que me parece o absurdo embananamento normativo fundamentalista de sua também teológica, anabatista, crítica da Modernidade e do Capetalismo (sic) como Mundo Virado. E, logo, o descabido da parte propositiva de suas análises, enredada a um humanismo crítico essencialista (no fundo até naturalista-rousseauísta), aquele do ser-genérico substancializado, que dá suporte à sua delirante narrativa de completa superação da alienação como dissolução da religião.

10 - LEONARDO: Todos os pontos anteriores, por fim, ligam-se com um questionamento a respeito da sua conclusão, momento em que você introduz uma derivação de consequências políticas e normativas do paradigma prático-poiético. Tendo em vista o caráter talvez excessivamente abstrato e amplo de seu ponto de vista, sua proposta normativa de uma democracia material também me parece possui um caráter pouco determinado. Como não vemos distinções, p. ex., entre práticas mais ou menos alienadas (ou algo do tipo) e mais ou menos autônomas, como tudo tem de se indiferenciar (o seu é "um ponto de vista menos inclinado a admitir determinadas práticas ou pontos de vista como transcendentais ou superiores, como de uma natureza totalmente outra, em detrimento das comuns, do comum dos homens"), sua democracia material parece adquirir um caráter meramente quantitativo. Nela apenas teríamos mais difusão de práticas, recursos, competências etc. entre os cidadãos, e, apesar de você mencionar a palavra transformação em um dado momento, ainda poderíamos nos perguntar como falar de transformação como democratização, se antes não foi definido nenhum tipo de critério de julgamento de práticas como democráticas? Me parece assim que sua proposta não contempla a possibilidade de estabelecer um critério normativo para pensar transformações mais qualitativas, ainda que pontuais, na sociedade. Podemos pensar talvez em quantidades maiores de recursos, meios e práticas, mas não vejo como pensar em meios materiais, artefatos, práticas ou técnicas diferenciadas..

CRISÓSTOMO: O ponto de vista prático-poiético quer de fato implicar num desdobramento crítico-político-social, democrático, apresentado no texto-resumo muito 
telegraficamente, apenas para que encontrasse registro. Mas creio que, diferente do que você parece entender, minha recusa de um "ponto de vista de Deus", transcendental, superior, a meu juízo não efetivamente político, eventualmente até despótico, no mínimo elitista ou vanguardista, resulta ela própria de uma preocupação democrática - normativa, portanto. De outro lado, minha ideia de uma democracia econômica, material, cidadã, não quer ter nada de meramente quantitativo. Embora, devo admitir que para mim mais comida, mais renda, mais educação, mais meios, mais conhecimento, mais produtividade, mais valor agregado, mais empoderamento, mais trabalho qualificado, mais patentes, mais inovação etc. - mais difundidos - já são por si maravilhas qualitativas e para mim fazem parte de qualquer coisa mais qualitativa que eu consiga pensar em empatia com aspirações sociais realmente sentidas. Em todo caso, pretendo além disso e com isso recuperar a mencionada ideia de autonomia, em uma dimensão mais rica, efetiva, prática. Dissociada de uma noção metafísica de sujeito, embora, vamos lá, ainda evocadora, em alguns de seus traços, de uma hegeliana Selbstbewusstsein (autoconsciência). Em Hegel, e para os hegelianos de esquerda não comunistas, uma noção louvavelmente normativa, e, até para Marx, o equivalente alemão da igualdade dos franceses, louvavelmente moderna. No meu caso, não para superá-la por um viés normativo apenas socialcoletivista, em Marx sublimado no seu dogma teleológico de um sujeito plenamente socialsocial como o único humano verdadeiro. Mas pelo seu envolvimento com possibilidades e potencialidades de um enriquecimento, empoderamento e validez mais efetivos, ao final também econômicos, dos seres humanos, da cidadania. Igualmente por virtudes e competências subjetivas, autorais, criadoras, e pelos direitos e poderes que lhes correspondam, que aquelas sustentem. Coisa de salutares implicações não só políticas, mas educacionais e culturais, além de econômicas, já hoje ecoadas em muitas iniciativas progressistas, qualitativas, do nosso tempo, em desenvolvimento nessas áreas todas. $\mathrm{O}$ que se pode considerar como uma versão materialista da autoconsciência como intencionalidade e autoatividade (sensíveis, mundanas) que para Marx só seriam reais no comunismo. Aqui em versão nem empirista-liberal, à la individualismo possessivo, britânico, nem consciencialista-solipsista, idealista, muitas vezes arrogante, às vezes até complicadamente anti-social e anti-democrática, à la romantismo alemão. Bem longe também do fundacionismo social forte comunista de Karl Marx, avesso, como já disse, a qualquer ideia de espontaneidade pessoal fora do comunismo. Avesso a que na atividade humana "o que se afirme seja o ato de por e não o ser posto", como ele receia, nos Manuscritos de 1844, contra Hegel. Entre desinteressado e incapaz de encontrar uma melhor conversão materialista, mas democrática, da autoconsciência de Hegel. Ao que nós agora 
retornamos, em versão prático-sensível, se você quiser por uma "quantidade" maior de autonomia como autoria e criação, espiritual-sensível. De cidadãos agora mais social e materialmente empoderados e livres, por desenvolvimentos também materiais e econômicos (ergo sociais). Mas desenvolvimentos mais bem projetados e mais empiricamente conciliados com uma realidade em dinamismo aberto, compreensivelmente fora do script histórico comunistizante por Marx projetado, supressor da suposta base material daquela autoconsciência: a pequena burguesia. Ficamos em vez disso com uma continuação - a ser imaginada, inventada, experimentada - da revolução político-social mais geral da Modernidade, aquela da convergência de democracia e liberalismo, de liberdade e suas "condições materiais e institucionais" de possiblidade. Dentro disso, não há por que a atividade de agregar valor (econômico, sim), conhecimento, imaginação, arte, espírito, à atividade produtiva dos homens não tenha interesse transformativo, normativo, qualitativo, filosófico, apenas porque emancipação em Marx sempre foi buscada - com os resultados que sabemos - na direção oposta. Por envolver manifestamente a nosso enredamento prático-poiético-material, social, com o mundo, ela não precisa abrir mão de uma compreensão socializada e intersubjetiva de racionalidade, e de verdade como - também - justificação. 